\title{
MUJER Y DOMINICANIDAD EN LA OBRA DE VIRGINIA ELENA ORTEA
}

\author{
Luis A. Jiménez
}

\begin{abstract}
RESUMEN
Dentro del discurso estético del Caribe fin-de-siglo, Virginia Elena Ortea ejemplifica a una mujer en búsqueda de la dominicanidad. La voz de Ortea ocupa un espacio integral del imaginario nacional colectivo. La autora dominicana manifiesta su ardiente patriotismo y su concepto de Nación, lo mismo que la desmitificación del papel de la mujer en la sociedad y su deseo de colocar el cuerpo femenino en el centro del discurso oficial.
\end{abstract}

\begin{abstract}
Within the turn-of-the-century Caribbean aesthetic discourse, Virginia Elena Ortea exemplifies a woman in search of Dominicanness. Ortea's voice occupies an integral space in the collective national imaginary. The Dominican author manifests her ardent patriotism and concept of Nation, as well as the demythification of woman's role in society and her desire to place the female body at the center of the official discourse.
\end{abstract}
Seys son las que se van, yo sola quedo: el alma lastimadas las partidas partida de dolor, porque partida partió y cortó el contento de mi vida Cuando con gran contento la gozaba.

Doña Leonor de Ovando

El epígrafe proviene de una composición escrita en versos blancos por la primera poeta criolla de América, profesa en el Monasterio de Regina en Santo Domingo en el siglo XVI. También la literatura dominicana del siglo XIX cuenta con tres nombres ilustres: Salomé Ureña de Henríquez (1850-1897), poeta patriótica de inspiración eminentemente civil, Josefa Perdomo y Heredia (1834-1896), voz lírica de la poesía religiosa y Virginia Elena Ortea (1866-1903) a quien Joaquín Balaguer considera la escritora dominicana decimonónica "mejor dotada para la actividad literaria" (1992: 166), juicio inspirador ya que hasta el presente, Ortea es una figura clave de la literatura finisecular poco estudiada por el discurso crítico contemporáneo. 
De padre y madre de origen puertoplateño, tuvo que emigrar a Puerto Rico a una temprana edad, debido a las persecuciones políticas que sufría "Dr. Franck" pseudónimo que empleaba su padre, Francisco Ortea. Dejó una corta producción literaria que consta de unos pocos poemas, una zarzuela inédita "Las Feministas" (1899), una novela inconclusa Mi hermana Catalina (1897) y Risas y Lágrimas (1901), libro que recoge páginas autobiográficas, relatos costumbristas y varios cuentos de corte modernistas ${ }^{1}$, dos de ellos publicados originalmente en Revista Ilustrada de Santo Domingo ${ }^{2}$.

Su amor lírico por las flores ("lirios", "malvas", "azucenas", "jazmines”), especialmente "la rosa blanca" o "la airosa palma" en busca de la patria ideal (63-64), es tropo referencial de José Martí; la obsesión por la muerte de sus personajes femeninos aparece como huella innegable en la escritura casaliana, lo mismo que su insistencia en el decorado azul que privilegia el discurso rubendariano. Cabe agregar que trozos discursivos de estos autores aparecieron esporádicamente en la Revista Ilustrada donde publicaban también dominicanos del parnaso modernistas de la época como Gastón Deligne y Tulio Cestero, ávidos lectores del discurso eurocéntrico, paradójicamente proveniente de la España católica (Bécquer, Espronceda), la Inglaterra victoriana (Wilde, Swinburne) y la Francia fin-de-siglo (Verlaine, Mallarmé y José María Heredia, autor de Los Trofeos e hijo del dominicano Domingo Heredia y Mieses). Simplemente, todo esto prueba que Ortea conocía a fondo las corrientes renovadoras durante el momento de su escritura.

También en boga y colaborando entre el espacio hegemónico de los hombres letrados hispanoamericanos de su época, existe la preocupación fin-de-siglo de Ortea por alzar su voz dentro de la cultura dominicana en que se desenvolvía. Se puede afirmar que la mujer dominicana de entonces contaba poco en la "realidad" nacional donde la literatura se asociaba a la formación teleológica y simbólica del Estado-Nación, y con su ficcionalidad interpolaba a los ciudadanos en sujetos. En las dos últimas décadas del siglo XIX, la República Dominicana experimentaba una era transitoria, presenciaba una algarabía política y económica que hacía oscilar a la sociedad entre el dominio terrateniente y la política, norte contra sur, tabaco contra azúcar, economía rural contra un incipiente neocolonialismo de fachada urbana (Vallejo 1997: 12).

Al hablar sobre la mujer dominicana finisecular, Tomás Báez apunta que ya en esta época se integra con voluntad firme y prometedora de amplios horizontes, hacia los nuevos senderos y abrirá las puertas de su liberación (1998: 191). Dentro del paradigma de un complejo sociodiscursivo, estos nuevos caminos a que hemos aludido desmitifican y crean la construcción del sujeto femenino a nivel nacional y bajo la captación global de la dominicanidad. Nos encontramos en la situación de un Estado-Nación, acalorado por una creciente sociedad burguesa de consumo donde la discriminación de la mujer es totalmente inaceptable.

Algunos de los brotes nacionalistas y feministas de Ortea se reflejan tenuemente en el discurso narrativo de Risas y Lágrimas donde el 'yo' discursivo establece lazos familiares con su difunto padre y, a su vez, le confiesa nostálgicamente su "rebeldía" de mujer desterrada de aquella "lejana tierra que tus hijas no han podido engalanar" (25). Concepto patriótico y regreso al mito, el viaje a la tierra prometida, invocación de exiliada, futura madre de la Patria que no llegó a ser. De hecho, nostalgia, nación y mujer, sujeto válido de la historia dominicana, son constantes medulares e indisolubles en la técnica contestataria del ejercicio literario de Virginia Elena Ortea. A nivel de traslado del signo linguiístico, podemos decir que la comunicación discursiva entre el "yo" de la escritura y la "Otredad" patriótica se ajusta a la "regla de 
inmanencia" que discute María Amoretti, mediante la cual la primera persona gramatical se desposesiona de sí misma para identificarse con el "otro" distinto, pero afín a su imaginario nacional colectivo $(1997: 9)^{3}$.

Lo antedicho sobre el exilio y la nostalgia ${ }^{4}$, aparece en su poema de la lejanía, "Puerto Plata" (Mayagüez, Puerto Rico, 1889), ciudad donde fallece en $1903^{5}$. Nos inicia al discurso patriótico de la dominicanidad con breves trozos descriptivos que oscilan entre la naturaleza y lo que recuerda como nostalgia asertiva. La voz lírica asocia el paisaje puertoplateño de "espuma blanca de su pintoresca playa" a sus vivencias infantiles: "la ciudad querida,/ nido de mi alegre infancia,/ que guarda de los recuerdos del alma" (32). En la segunda estrofa, expresa su manera de sentir de desterrada: "un asilo cariñoso/ pedir a esta tierra amada" (32). Desde una óptica sicológica, la referencia a la lejana "tierra amada" implica el anhelo de regreso al paraíso perdido, parafraseando el título del libro de Mario Jacoby.

En la tercera estrofa, se comunica nuevamente con su interlocutora, la "tierra amada" que identifica metafóricamente como "nube de plata", armonías o juegos de palabras con Puerto Plata, y que globalmente define, expresa y limita "los confines de mi patria" (32-33), el terruño dominicano que la hablante recrea. En el golpe poético de la estrofa final culpa a la "suerte impía" que la desterró cruelmente de la República Dominicana y, desesperanzada, confía que el entusiasmo anímico dé tregua a la nostalgia, la acerque al "altar de la patria" (33). Memoria y nostalgia parecen ser puntos definitorios del momento histórico de la escritora en un intento por desmitificar la fábula del exilio involuntario. La instancia poética recurre a lo sagrado, lo incontaminado, la piedra simbólica del sacrificio, con aspiraciones a plantar la cosecha nacional, germinación integral de una cultura futura que también instaba su compatriota Salomé Ureña de Henríquez en condiciones políticas ajenas a las de Ortea. Ambas mujeres, sin embargo, siembran la coyuntura histórica dominicana donde la figura letrada ocupa un lugar eminente porque expone "verdades ocultas" y adopta las "vestimentas de un profeta laico" (Rodríguez 1988: 513), lo que equivale a decir que fructifica la arcilla seminal conciudadana.

"En la tumba del poeta" de Risas y Lágrimas, cuento alegórico con referencias mitológicas, Ortea muestra gran maestría en el arte de contar ${ }^{6}$. Narrado en forma de sueño, aparece la luna en la primera sección del discurso, plasmada en una mujer de "rostro mofletudo y sonriente" (66), como si se anticipara esta figura alegórica a la poesía lorquiana. En la experiencia onírica, esta luna, [la "Madre del Universo", según Walker (1983: 669)], persona literaria simbólica y mitológica a la vez, crea lazos comunicativos con la narradora, lo que llama, en términos poéticos, "mi nueva compañera de entrelazadas manos" $(66,68)$. Más adelante, la luna le cuestiona si conoce "algún Edipo moderno" (67). En efecto, la conversación entre el sujeto de la narración y el sujeto alegórico gira en torno a la versión edípica, el concepto hijo/madre que Ortea moderniza mediante la intercalación de una "pobre huérfana con encajes su vestido de novia" en el relato (67). Artísticamente hablando, revierte el mito griego de Yocasta ya que el amante no es su hijo y éste "muere en los brazos de la mujer", el cuerpo femenino desmitificado (67). Como feminista, Ortea destruye el mito porque la "mujer huérfana" permanece viva, haciendo de este motivo mitológico una especulación cuentística.

En la primera sección del discurso, ocurre una metamorfosis ya que la luna se convierte en la diosa de la Fatalidad "caprichosa y coqueta" (68), cualidades femeninas que le dan sabor humano a la narración. A través de la Fatalidad, la narradora intercala otra historia que nos recuerda los cuentos orientales o la invención cervantina, creación de una ficción dentro 
de otra. En el segundo cuento intercalado, aparece otro personaje femenino, la princesa, hija de una emperatriz, cuya corte se desconoce por pertenecer al mundo de la "fantasía" de Ortea. Nuevamente, nos encontramos con la reversión y el juego con el mito edípico: se elimina al hijo, a favor de la relación (no amorosa, cabe aclarar) madre/hija. Ficciones sobre mujeres que demuestran el interés discursivo de la autora dominicana por incluir su propio sexo en el cuerpo de la escritura para gestar la construcción de sujetos femeninos elaborados con codificaciones estéticas originales y montajes narrativos reveladores.

La princesa, convertida en reina por la Fatalidad, se ve sujeta a las fisuras provocativas y a las reglas destructivas del juego de ésta, quien provoca un incendio en la ciudad imperial. Dentro del contexto semiótico de la trampa, este juego provoca "la siniestra luz señal de mi presencia" (69). Odiada y envidiada por las "viles cortesanas", la princesa continúa la línea tradicional de la matriarca, bajo el amparo universalista de este tipo de discurso (luna-princesa-reina-madre $^{7}$ ), jerarquiza su poder casi extinguido por las llamas, e intenta colectivizar sus sentimientos. En un golpe expresivo de perplejidad, alumbra, por primera vez, al varón olvidado y apropiándose de las garras agresivas del lenguaje "recordó que era madre", pidiendo así por "la salvación de sus hijos", ciudadanos de una Patria alegóricamente fragmentada por la voz fecunda de la Fatalidad. Al mismo tiempo, apunta hacia una sociedad dominicana dividida por grandes alborotos políticos y económicos de aquella época.

En la última sección del relato, la Fatalidad acompaña a la reina al suplicio, descanso final representado por el ataúd que productivamente "costó al Estado seis francos" (70), alusión monetaria y foco esclarecedor de un discurso proveniente de cualquier cultura neo/pos/colonial, y, en especial, la dominicana. En definitiva, el personaje fallece con la dulzura de su "primer sueño", a lo que hay que añadir el "último sueño" o la "imaginación fogosa", nexo sorjuanesco que la narradora improvisa, y que sugiere significados múltiples e intertextuales de la enunciación discursiva. Mediante bromas muy castellanas, toma "por lazarillo á [sic] la reina de la noche". O sea, el simbolismo de la luna se vincula a la fantasía nocturna de Ortea, después del retorno de la luna a la tierra, el regreso al mito al final del cuento. Visto dentro de un marco mitológico (en Grecia, India e Irán, por ejemplo), la ausencia de la luna coincide con la muerte, y regresa de su viaje al cuarto día, lo que implica el retorno de la mujer al mito (Cirlot 1991: 216).

"Las Feministas", zarzuela en dos actos con letra de Virginia Elena Ortea, fue dedicada a la sociedades puertoplateñas en octubre de $1899^{\circ}$. Indudablemente, la escritura, la preservación y la transmisión de este discurso musical, abren la brecha al escrutinio feminista en búsqueda de una relación entre la mujer, dominicana en este caso, y la musicología ${ }^{9}$. Como señala Catharina Vallejo, la pieza refleja el feminismo decimonónico en casi todas sus facetas, y simultáneamente evidencia algunas de las paradojas de este "quehacer feminista" (1997: $18)^{10}$,"quehacer" que se considera un reto decisivo a la cultura hegemónica de la dominicanidad en el siglo XIX. Ahora bien, ¿por qué emplea Ortea el arte del canto en la escritura para expresar su sensibilidad de mujer caribeña? Digamos, para empezar, que la polivocidad simultánea de las interpretantes de la zarzuela se encarga de transcribir por medio de la oralidad los contenidos de la mujer dentro de su propia cultura.

Cándida, viuda y presidenta de "Las Feministas", es la figura central y el vocero oficial que abre el discurso musical, cuyo canto (generalmente las mujeres crean los cantos de la Patria) consiste en "emancipar a la mujer ¡del hombre!" (67). De inmediato, entona la "guerra 
declarada" entre los sexos, y con justicia reclama "escalar del mundo puesto que nos negó el egoísta. [H]acer que valgan nuestros derechos. El hombre es un tirano" $(67,68)$. El aire melódico, subversivo para la época, se repite varias veces en la enunciación discursiva con intención de trasladar a la mujer de la periferia al centro de la escritura, mediante la representación de un espectáculo, cuyo significante se traduce inicialmente como "esclavas" (69) en el escenario o en el mundo carnavalesco "de [la] comparsa" (74), si queremos asociarlo a Bakhtin. Por esta razón, las feministas de la zarzuela deben abandonar la candidez, estrategia del disimulo onomástico que la palabra ofrece, o dicho de otra manera, estas mujeres no tienen nada de cándidas. El propósito de la reunión -señala Cándida- es "levantar bandera, para alzar en rebeldía a la mujer" (69).

Este alzamiento metonímico (el canto como rebelión) de Cándida se refuerza cuando lee a la junta feminista el discurso proveniente de Francia. Triple gesto del lenguaje-lectura-canción-escritura que primeramente condensa la embrollada interpretación del mito edénico. Expliquemos lo antedicho. Eva, antes de ser madre, se encuentra en posición de igualdad en relación con Adán. Dice Cándida en su discurso incendiario: "Creó Dios a la mujer/mitad bella i [sic] preciada/para ser igual del hombre,/no su inferior" (72), para luego intercalar elocuentemente, y con enumeración casi caótica, a personajes históricos y literarios como Juana de Arco, Isabel de Castilla, Carlota y Judith, Santa Teresa y Madama Roland, todas figuras gino/euro/céntricas de la cultura occidental. ¿Por qué omitiría a Sor Juana, si ya vimos el "primer sueño" intertextualmente expresado en el cuento "En la tumba del poeta"?

Como mujer progresista consciente de que "hay que" hacer algo, Cándida exhorta a las "Dignas hijas de este siglo" para que abandonen el sortilegio de la coquetería femenina, y denunciar la verdad silenciada de la época. Canta en tono cálidamente exclamativo:

\author{
¡hay pueblos de historia heroica \\ porque hubo mujeres bravas! \\ Más, hai [sic] que renunciar, dignas \\ nobilísimas hermanas \\ a toda sensibilería $(72,73$, destacado agregado).
}

Habla simplemente de hermanas porque, en realidad, la actuación discursiva de Cándida es de mujer viuda, no de madre (Ortea no lo llegó a ser), aunque menciona brevemente que tiene seis hijos. De ahí, la ausencia del papel materno en la zarzuela (otra vez Eva, en función de mujer sin prole en el canto). Lo que se establece en este enunciado es el concepto de "sororidad" "1, la comunidad o la colectividad entre las mujeres del teatro, bien sean las actuantes en la zarzuela o las oyentes en el público, que están bajo la escrutinadora mirada masculina.

La rebelión de Cándida y sus seguidoras se organiza para lograr trozos de la vida social (educación, hogar, matrimonio, sexualidad, familia), y para establecer lazos humanos y encontrar con cierto sentido nacional un sitio en otro espacio privado de la cultura dominicana. Necesidad de adquisición cognoscitiva y poder, diría María Amoretti, puesto que el lenguaje se apoya en ambos, hace de ellos la representación de la cultura donde se origina. Al caer el telón, triunfa la esfera íntima del matrimonio porque se casan las feministas. Sin embargo, en búsqueda de su femineidad (o feminismo), Cándida no se resigna a ser objeto físico del Deseo, como lo reconoce Inocente, pretendiente de la protagonista, "hombre fin de siècle (109, cursiva de la autora) que lo confiesa en la alabanza a la mujer al final de este discurso musical: "El progreso 
la engrandece,/ la ilustra, ¡Siempre será nuestra dicha! (115, cursiva agregada). Este subrayado, cantado reiteradamente en la zarzuela, apunta hacia una tregua entre los sexos, resolver la batalla por medio del matrimonio. Al inmiscuir a Inocente (nuevamente otro juego onomástico de Ortea) en el discurso, se borra el sujeto colectivo femenino y se entroniza la institución patriarcal del matrimonio, que favorece la unión feliz de la pareja, y que culminará con la entrega de dos cuerpos, conclusión que matiza y satisfece al género de la zarzuela. La pieza termina con un registro oral, el canto, y otra estrategia retórica, la risa; esta última irónicamente induce a la reflexión de la mujer, arquitecta integral de su comunidad y de su propio destino.

Mi hermana Carolina consta de treinta y siete páginas de un manuscrito inconcluso donde se dialoga con el caso paradigmático de la novela sentimental de manera muy diferente (Vallejo 23, 24). En ese corto texto, Ortea exhibe dotes artísticos en el arte de narrar desde el punto de vista del narrador masculino en primera persona, el adolescente Luis. Este especula sobre el sujeto femenino romántico y el sujeto feminista fin-de-siglo, ambas fragmentaciones que se observan en Catalina, la joven huérfana que viene a residir a la casona rural. Al igual que lo visto a través de la escritura orteana, en este discurso novelesco se mantiene siempre el concepto de nación dominicana: “Qué hermoso rincón de mi patria era aquel," exclama Luis (49).

Pero a diferencia del cuento o la zarzuela, en este otro libro la autora dominicana le permite al varón apropiarse del discurso patriarcal predominante en aquel entonces. Este trueque linguístico (el "yo" masculino de Luis en vez del femenino de Catalina) reviste la máscara de la "otra", quien es realmente la que satura la importancia de la mujer en el texto, mujer desdoblada en dos entes de ficción en complicidad certificada con el/la lector/a (Amoretti 1994, Chen Sham 219-27). Cabe agregar que, de la manera que percibimos a Luis, pertenece al sexo débil, en el sentido de que es el hombre que se estremece con su añoranza por el cuerpo de la mujer, y no Catalina que ansía o busca el encuentro físico o emocional, típico de la heroína romántica. El hombre permanece distante, observando y juzgando al "otro" femenino. Por otro lado, la mujer no parece interesarle tanto por sí misma o por lo que ella pueda decir, sino como Luis vagamente la ve, lo que crea a un personaje cuya silueta psicológica arroja una evidente crisis de identidad social y sexual.

Primeramente, se evidencia un sujeto femenino romántico porque las descripciones iniciales del narrador llevan este tipo de enfoque. El enmarque calificativo que Luis pinta antes de conocer a Catalina se perfila de "rubia", "sonrosada", "hermosa como un ángel" (50) del hogar. En función de "héroe", sueña con la "esperada huéspeda", sacada del intertexto romántico "pasado de moda", pero queriendo ser el "Pablo de la más encantadora Virginia" (50). La llegada de Catalina es decepcionante para Luis. Al ver en ella, "una niña pálida y desgarbada, vestida de luto, sus cabellos oscuros mui [sic] cortos" (51), se destruye la primera imagen soñada de la mujer para forjarse una sombra triste que es incluso parte de sus lecturas románticas sacadas de la novela que lee su madre. Catalina queda, pues, confinada al espacio doméstico, y en particular, al jardín de la casa donde confecciona ramilletes.

No obstante el autoengaño de Luis con su decepción de la fea y llorona (152, cursiva de la autora) Catalina, le obsequia con una jaula que él mismo construye, regalo que la joven rechaza al pedirle que le dé la libertad al par de ruiseñores. Este acto simbólico por parte del personaje indica su derecho a la independencia, descartando posibles binomios que implican ataduras, jaula-ave, cárcel-mujer. 
En segunda instancia, es sujeto feminista fin-de-siglo por dos razones. Primero, porque se le concede compartir con Luis las clases del profesor, quien considera a Catalina "muy lista" (55). Este gesto orteano por proclamar el derecho de la mujer a la educación era interés común entre las escritoras hispanoamericanas de aquellos tiempos (la educadora cubana María Luisa Dolz y la puertorriqueña Ana Roqué de Duprey, por citar a algunas) en un intento por desmitificar a la mujer moderna. Y segundo, existe el carteo con Luis después que este reside en Francia para estudiar. La escritura de Catalina indica que la mujer sabe producir discurso, y al firmar los documentos en una provocativa aventura epistolar, deja sellado su nombre en las páginas de este fragmento textual. Es sujeto feminista en el sentido de que el análisis de las cartas cuestiona el orden patriarcal establecido y propone una visión de la condición femenina; es decir, la mujer-persona con conocimiento, autonomía discursiva y poder, tres inquietudes latentes en todo lenguaje. Se podría desarrollar lo que pudiera convertirse en una larga disertación sobre el tema de la sabiduría de la mujer tan obvia en el texto, por eso se concluye simplemente con la reacción de Luis que dice: "las mujeres no deben saber tanto", lo que sirve de interrogación a la voz materna que habla en el discurso, "Para que no vean a Uds. [los hombres] los defectos?" (56).

Ya sea en la poesía, el cuento, el ensayo periodístico, la zarzuela o el intento novelístico, el discurso polifacético de Virginia Elena Ortea muestra la preocupación de la mujer dominicana por insertarse en los cánones oficiales de una cultura patriarcal dominante, que aceptó una semilla fructífera, metafóricamene hablando, y acató su voz y su contribución estética a las letras nacionales. Por su afiliación "modernista" junto a la cubana Juana Borrero y la puertorriqueña Carmen Eulate Sanjurjo, por su condición de mujer letrada progresista y patriótica como su amiga Salomé Ureña de Henríquez, y más importante aún, por ser mujer desterrada al igual que Lola Rodríguez de Tió, cantante de su Patria también venerada por su pueblo, Ortea permanece estrechamene vinculada al legado literario de nuestro Caribe fin-de-siglo.

\section{Notas}

* Quisiera darle las gracias a Daysi M. García, de la Biblioteca Nacional de Santo Domingo, por permitirme fotocopiar Risas y Lágrimas (1971), y asistirme en la búsqueda de los números de finales del sigló XIX de Listín Diario, periódico nacional en el que escribía Ortea. Afortunadamente, Catharina Vallejo los localizó antes que yo, y aparecen referidos a la obra de Ortea en su reciente libro.

1. Para el cuento modernista de Ortea, véase mi artículo (13-20).

2. Como no existen los dos textos decimonónicos de Ortea, citamos del libro de Catharina Vallejo.

3. Productora de un discurso nítidamente nacional, Amoretti desconstruye a fondo el mito telúrico a través de la costarricensidad en la obra de Magón (véanse obras citadas). Ya sea el campesino costarricense, el jíbaro puertorriqueño, el guajiro cubano o el llanero venezolano, por mencionar sólo algunos, este discurso poscolonial traspasa barreras nacionales porque pretende establecer globalmente nuestra identidad americana. El discurso crítico de Amoretti lo considero digno de exportación crítica.

4. El término "nostalgia" fue inventado por un médico suizo del siglo XVII para vincular el estado de añoranza de la patria con el ánimo de mercenarios suizos que peleaban en territorios lejanos. Proviene del 
griego nostos (regreso al hogar) y algos (una situación dolorosa). Se consultó la "sociología de la nostalgia" de Fred Davis.

5. Escribió varios poemas más que aparecieron en revistas de la época: "Àbreme" (1889), "A un poeta" (1889), "La vuelta" (1890), "Rimas. Para el álbum de Lola" (1891), "Psiquis" (1901), Traducido libremente del inglés.

6. Sin entrar en la difícil definición de alegoría, se podría decir que con su empleo pretende comunicarle al destinatario algunas formulaciones generales sobre la organización jerárquica del mundo (véase Clifford 1974: 7).

7. En "Romance de la luna, luna" de Federico García Lorca, el personaje alegórico simboliza la muerte del niño que la luna intenta seducir (Diana, la cazadora mítica). Sin estas connotaciones eróticas, la luna en el cuento de Ortea sencillamente provoca la muerte de la princesa-reina-madre.

8. Para un estudio del teatro dominicano en el siglo XIX, veáse el libro de José Molinaza.

9. Para el desafío de la mujer a través de la música, veáse Joseph Kerman.

10. Por esta fecha, María del Pilar Sinués escribía mordaces comentarios en defensa de la mujer, publicados en el periódico puertoplateño El Porvenir, entre 1893 y 1894 (Vallejo 18).

11. Uso el término tal como lo usa Marcela Lagarde en su ensayo sobre cultura feminista: "[s]ignifica la amistad entre mujeres diferentes y pares, cómplices que se proponen trabajar, crear, y convencer, que se encuentran y reconocen en el feminismo, para vivir la vida con un sentido profundamente libertario" (79).

\section{Bibliografía}

Amoretti Hurtado, María. 1998. "Dos vivazos y un tonto en un certamen de mentiras". Káñina. 22 (2): 9-27.

1999. "El discurso imperecedero de Magón”. Káñina. 23 (2).

1997. "Propuestas metodológicas para una lectura diferente de los textos de Magón". Káñina. 21 (2): 165-73.

1997. "Siempre queremos saber quién habla". Revista de Filología y Lingüística de la Universidad de Costa Rica. 23 (1): 7-23.

Baéz Díaz, Tomás. 1998. La Mujer aborigen. La Mujer en la colonia. La Mujer dominicana. Santo Domingo: Ediciones de Colores, S.A.

Balaguer, Joaquín. 1992. Historia de la Literatura Dominicana. Santo Domingo: Editorial Corripio.

Chen Sham, Jorge. 1994. "La fuerza centrípeta y la noción de imperio en 'La Gramática Castellana' de Nebrija”. Káñina. 18 (1): 219-27. 
Cirlot, J.E. 1991. A Dictionary of Symbols. Trad. Jack Sage. New York: Dorset Press.

Clifford, Gay. 1974. The Transformation of Allegory. London: Routledge \& Kegan Paul.

Davis, Fred. 1979. Yearning for Yesterday. A Sociology of Nostalgia. New York: The Free Press.

Jacoby, Mario. 1985. The Longing for Paradise. Psychological Perspectives on an Archetype. Boston: Sigo Press.

Jiménez, Luis A. 1998. "El sujeto femenino fin-de-siglo en la cuentística de Virginia Elena Ortea". SELA. 42 (1): 13-20.

Lagarde, Marcela. 1992. "Enemistad y sororidad: Hacia una nueva cultura feminista". Isis Internacional. 17: 55-82.

Kerman, Joseph. 1988. Contemplating Music. Challenges to Musicology. Trad. Betsy Wing. Minneapolis: U of Minnesota P.

Ortea, Virginia Elena. 1978. Risas y Lágrimas. Santo Domingo: Editora "Alfa y Omega".

Rodríguez Pérsico, Adriana. 1988. "Argirópolis: un modelo de país". Revista Iberoamericana. 143 (abril-junio): 513-23.

Vallejo, Catharina. 1997. Virginia Elena Ortea. Obras. Santo Domingo: Editora Búho.

Walker, Barbara G. 1983. The Woman's Encyclopedia of Myths and Secrets. San Francisco: Harper Collins Publishers. 